\title{
ELABORAÇÃO DE PRODUTOS PANIFICADOS COM A UTILIZAÇÃO DE FARINHA DE ALBEDO DE MARACUJÁ, EM SUBSTITUIÇÃO À FARINHA DE TRIGO
}

Fernanda Antonia de Souza Oliveira ${ }^{1}$; Aurora Britto Andrade ${ }^{2}$; Weena Rebeca Pinheiro Damasceno2; Rebeca dos Reis Magalhães Azevêdo ${ }^{3}$; Renato Souza Cruz; ; Janaina de Carvalho Alves²; Karina Lizzeth Pedraza Galvão²

da

Bahia;

Salvador/Bahia;fernandaasouzaoliveira2@gmail.com

2 Universidade Federal da Bahia; Salvador/Bahia

${ }^{3}$ Universidade Estadual de Feira de Santana; Feira de Santana/ Bahia

Resumo: O maracujá, fruto de significativa produção nacional, possui $52 \%$ do seu peso compreendido por casca (albedo), sendo rica em pectina, além de possuir propriedades tecnológicas importantes para os produtos de panificação. No presente trabalho foi realizada a produção da farinha de albedo de maracujá (FAM), posteriormente usada em diferentes concentrações para produção de macarrão $(4,8$, 12 e 16\%) e biscoito (3, 6, 9 e 12\%). Análises físicas e tecnológicas foram realizadas para caracterizar os produtos. O tratamento de dados, mostrou que a concentração ideal de FAM para o macarrão é de $15 \%$ e para o biscoito a incorporação máxima não apresentou uma diferença significativa. Conclui-se que a FAM apresenta grande potencial para o uso na panificação, se fazendo necessários ajustes complementares.

Palavras-Chave: macarrão; biscoito; farinha de albedo de maracujá.

\section{ELABORATION OF PRODUCTS PANIFIED WITH THE USE OF ALASSED PASSION, IN REPLACEMENT OF WHEAT FLOUR.}

\begin{abstract}
Passion fruit, the fruit of significant domestic production, has $52 \%$ of its weight comprised of peel (albedo), is rich in pectin, and has important technological properties for bakery products. In the present work the production of passion fruit albedo flour (FAM) was carried out, later used in different concentrations to produce pasta $(4,8,12$ and 16\%) and biscuit (3, 6, 9 and 12\%). Physical and technological analyzes were performed to characterize the products. The data treatment showed that the ideal concentration of FAM for pasta is $15 \%$ and for the cookie the maximum incorporation did not present a significant difference. It is concluded that the FAM has great potential for use in baking, making necessary further adjustments.
\end{abstract}

Keywords: Pasta; biscuit; passion fruit albedo flour. 


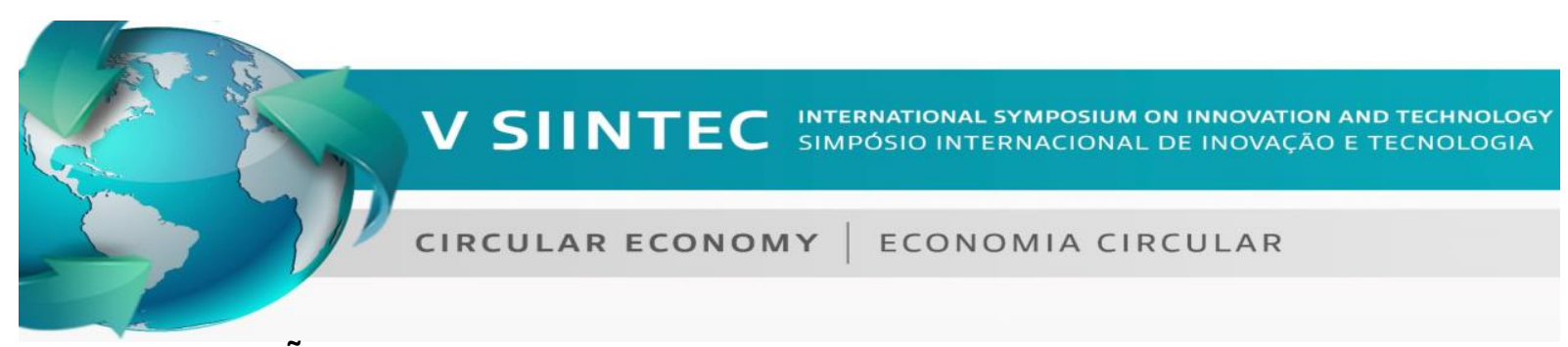

\section{INTRODUÇÃO}

O fruto maracujá (Passiflora edulis), é cultivado no Brasil, sendo a região Nordeste o principal produtor com $60,92 \%$ de toda a produção nacional, correspondendo a 337.881 toneladas/ ano. O maracujá é originário da América Tropical, rico em vitamina $C$, cálcio e fósforo $[1,2]$

A utilização do maracujá é concentrada na produção de sucos, mas outros produtos podem ser preparados utilizando a polpa, como em: confeitos para a produção de conservas, néctares, xaropes, sorvetes e outros produtos gelatinosos. A produção de sucos, se utiliza apenas da polpa e sementes do maracujá, o que representa cerca de 6 a $12 \%$ do peso total dos frutos, com alguma variação conforme a espécie do fruto e as cascas representam $52 \%$ do peso total do fruto[3,4].

A casca do maracujá, que representa o resíduo gerado pela indústria, é composta por flavedo (parte com coloração amarela ou roxa) e albedo (parte branca), esta última rica em pectina, espécie de fibra solúvel que auxilia na redução das taxas de glicose no sangue, fonte de niacina (vitamina B3), ferro, cálcio, e fósforo. Além disso a pectina apresenta propriedades gelificantes úteis na indústria de alimentos $[3,5]$. O albedo de maracujá apresenta alto teor de fibras $(67,5 \%$ base seca) e considerável quantidade de proteína $(6,8 \%$ base seca) e minerais como potássio $(25,5$ mg.100 g ${ }^{-1}$ base seca), ferro $\left(0,5 \mathrm{mg} .100 \mathrm{~g}^{-1}\right.$ base seca), sódio (19,1 mg.100 g ${ }^{-1}$ base seca) e cálcio (14,6 mg.100 $\mathrm{g}^{-1}$ base seca), bem como alto teor de pectina $(27,8 \%$ base seca) [6].

O segmento de panificação gera em torno de 800 mil empregos diretos e 1,8 milhão de forma indireta, nas cerca de 70 mil padarias e confeitarias existentes no Brasil. O ano de 2018 apresentou um crescimento na ordem de 2,81\%, o que equivaleria a um faturamento de $R \$ 92,63$ bilhões. A produção de trigo no Brasil, equivale a uma área estimada em 1,99 milhão de hectares, 2,4\% menor que a área plantada no ano de 2018, a produção estimada é de 5,5 milhões de toneladas [7].

No mundo estima-se que milhões de pessoas morrem de fome por ano, em decorrência da desnutrição, anemia por carência de alimentos, e, ou por conta de doenças diarreícas agudas. Em contrapartida a essa situação, o Brasil descarta milhões de toneladas de resíduos sólidos provindos da agroindústria. A utilização desses resíduos é uma forma da redução de contaminações ambientais e podem ser utilizados como uma possível fonte alimentar, rica em fibras e nutrientes, de baixo custo, seguindo o segundo objetivo da Agenda 2030 das Organização das Nações Unidas - ONU no Brasil, de fome zero e agricultura sustentável. A pesquisa foi realizada com o objetivo de agregar valor nutricional aos produtos macarrão e biscoito por meio da substituição parcial da farinha de trigo por farinha da casca do maracujá, com alta qualidade tecnológica e de baixo custo.

\section{METODOLOGIA}

\subsection{Preparo da Farinha}

O albedo de maracujá (roxo e amarelo) foi cortado em fatias, e destinados à etapa de secagem em secador de bandeja, com circulação forçada de ar, com temperatura 
de $80^{\circ} \mathrm{C}$ por $8,5 \mathrm{~h}$. Para determinar as curvas de secagem da farinha foram tomadas medidas do teor de umidade a cada 2 horas, até o momento que a umidade do albedo se encontrou entre 10 e 13\%, abaixo do limite máximo de 15\% [8]. Em seguida, foram trituradas em moinho de faca (TECNAL, TE-651) e peneirada com peneira vibratória de abertura de 30 mesh, acondicionadas em embalagens plásticas de polietileno de alta densidade com $50 \mu \mathrm{m}$ de espessura e armazenadas em temperatura ambiente, $25 \pm 2^{\circ} \mathrm{C}$ para análises seguintes. As farinhas foram caracterizadas quanto à granulometria [9], a umidade pelo uso de balança de infravermelho e a absorção de água (ABS) com resultados expressos em porcentagem (\%) de absorção.

\subsection{Elaboração de Produtos}

\subsubsection{Macarrão}

A massa alimentícia fresca foi processada em extrusora indiana modelo Pasta Mini 5" (Água Rasa-São Paulo), contendo rosca com taxa de compressão 1:1 e trafila para talharim com 23 orifícios retangulares de $1 \mathrm{~mm} \times 5 \mathrm{~mm}$, revestidos internamente com teflon. A massa foi amassada, misturada e extrusada, e em seguida seca em secador de ar forçado para dá prosseguimento as análises, Os parâmetros avaliados foram: tempo de cozimento método 66-50 [10], aumento de peso, aumento de volume e perda de sólidos solúveis. A textura das massas alimentícias cozidas foi determinada utilizando-se o equipamento Texturômetro TA-XT plus com os acessórios A/LKB-F, HDP/PFS e A/SPR, para avaliação dos parâmetros firmeza e força de cisalhamento [10].

Foram desenvolvidas quatro formulações de macarrão incorporadas com a farinha de albedo de maracujá- (FAM) da variedade roxa, com concentrações de 4; 8; 12 e $16 \%$, além da formulação padrão (sem o adicional de farinha de albedo de maracujá) para comparação. A formulação é constituída de óleo 3\%, sal1,5\% e água.

\subsubsection{Biscoito}

Os biscoitos foram elaborados, com a incorporação da FAM da variedade amarelo nas proporções de F1 3\%; F2 6\%; F3 9\% e F4 12\%, além da formulação padrão (F0), na qual se encontra isentada a FAM, para afins de comparação. Todos os ingredientes, farinha de trigo, farinha de albedo de maracujá, açúcar, manteiga, sal e ovos, foram misturados em batedeira tipo planetária (Arno), sua massa laminada e cortada em retângulos de $2 \mathrm{~cm}$ de largura, $0,8 \mathrm{~cm}$ de espessura e $9 \mathrm{~cm}$ de comprimento, para o assamento e demais análises. As análises realizadas foram de perfil de textura da massa crua (dureza, adesividade, flexibilidade e coesividade) e a textura do biscoito (dureza e fraturabilidade) em texturômetroTA.XT.plus. Além disso, foram avaliados peso, diâmetro, espessura, fator de expansão e volume específico. AACC, Método 10-50 D [10].

\subsection{Análise Estatística}

Os experimentos foram conduzidos em delineamento inteiramente casualizado, com três repetições e avaliados por teste de média, Tukey, com $5 \%$ de probabilidade, utilizando o software SAS, versão 9.0. 


\section{RESULTADOS E DISCUSSÃO}

\subsection{Granulometria das farinhas de maracujá das variedades roxa e amarela.}

Os resultados obtidos na caracterização granulométrica das farinhas de albedo de maracujá, das variedades roxa e amarela foram de respectivamente $44,40 \%$ em peneira de 42 mesh $(0,355 \mathrm{~mm})$, e $47,05 \%$ nessa mesma abertura de peneira, indicando que as duas farinhas apesar de serem de variedades distintas apresentam granulometria semelhantes.

O tamanho de partícula do alimento após a moagem constitui aspecto importante no preparo de derivado de farinhas, tendo em vista que uma maior uniformidade da granulometria permite a elaboração de um produto final de melhor qualidade sensorial, principalmente, textura, sabor e aspecto visual, pois o alimento absorve água de forma homogênea resultando no cozimento uniforme do produto. Assim sendo, a granulometria da FAM, das duas variedades, não apresenta uniformidade satisfatória para o preparo de produtos de panificação [11].

\subsection{Umidade das farinhas de albedo de maracujá variedades roxa e amarela}

A farinha de albedo de maracujá apresentou a umidade de 10, $78 \pm 0,3 \%$ para a variedade roxa e 11,56 $\pm 0,3 \%$ para a variedade amarela. A umidade é um importante aspecto para a conservação da qualidade dos alimentos, já que esta pode influenciar diretamente a composição química, no desenvolvimento de microrganismo, reações químicas e enzimáticas, ocasionando dentre outros prejuízos a diminuição de vida de prateleira do produto [12]

\subsection{Capacidade de absorção de água pelas farinhas}

A análise de absorção foi realizada nas duas variedades de farinha de albedo de maracujá presente, em triplicatas. Foi também feita com farinha de trigo incorporada com a de albedo de maracujá nas proporções 5\%, 10\%, 15\%, 20\% e $25 \%$. Os resultados obtidos para FAM da variedade amarela, roxa e a farinha de trigo foram respectivamente 559,83 $\pm 1,36,549,84 \pm 0,17$ e 58,39 \pm 0,20.

Comparando os resultados entre os valores de absorção encontrados na farinha de albedo de maracujá, nas duas variedades, nota-se que estes são semelhantes. Além disso, a farinha de maracujá tem uma absorção muito superior quando comparada a farinha de trigo. Esse valor superior de absorção da FAM pode ser explicado pelo alto teor de fibras presentes na casca do maracujá, principalmente a pectina, quando comparado ao teor de fibra presente em farelos de cereais e leguminosas por exemplo. Sendo que esse elevado teor de fibra solúveis aumenta o valor nutricional dos alimentos, proporcionando uma redução a resposta glicêmica, ajudando em problemas como diabetes, problemas cardiovasculares e obesidade [13].

\subsection{Tempo ótimo de cozimento}

O aumento da incorporação da FAM na formulação da massa, gerou uma diminuição no tempo de cozimento de forma não significativa com média de 7,00 \pm 0,01 min. O tempo de cozimento é uma função da coesão da massa, pela interação das proteínas dos grupos gliadina e glutenina e do amido presente [14]. 


\subsection{Absorção de água}

A absorção, ocorre num modelo significativo descrito como 0,011[FAM] $+2,03$ com $R^{2}=0,83$, e seu aumento já era um fator esperado devido aos altos teores de fibras encontrados na FAM. As farinhas com maior teor de fibras e proteínas retém uma maior absorção [15]. Houve uma redução do tempo ótimo de cozimento, e uma maior absorção gerando um umedecimento e intumescimento mais rápido do amido, alçando a gelatinização em um tempo menor.

\subsection{Perda de Sólidos}

A perda de sólidos se dá por um modelo significativo com $-0,03[\mathrm{FAM}]^{2}+$ ,72[FAM]+ $6,24 \mathrm{com} \mathrm{R}^{2}=0,99$, os resultados obtidos mostram que a partir da incorporação de $5 \%$ de FAM já se obtém uma farinha de péssima qualidade, e o acréscimo só aumenta a perda de sólidos, sendo a perda máxima com a incorporação de $11,91 \%$ de FAM. Farinhas com maior granulometria e partes fibrosas, geram um aumento da perda de sólidos [11].

\subsection{Aumento de Volume}

Para este parâmetro obteve-se um modelo significativo descrito como 0,01 [FAM] $+2,42$ com $R^{2}=0,86$, um aumento da incorporação da FAM na formulação da massa gerou um aumento de volume de forma similar. Os parâmetros ganho de peso e aumento de volume estão relacionados à capacidade de absorção de água das massas durante o cozimento e dependem do formato do macarrão. $O$ aumento de volume é classificado como bom com valores na faixa de 200 a $300 \%$ [16], o que não ocorreu, encontrou-se valores abaixo, sendo apenas a incorporação de $12 \%$ satisfatória.

\subsection{Análise de Textura das Amostras}

\subsubsection{Macarrão}

\subsubsection{Firmeza}

Os resultados encontrados mostram um modelo significativo descrito como $0,401[\mathrm{FAM}]^{2}-12,36[\mathrm{FAM}]+332,6 \mathrm{com} \mathrm{R}^{2}=0,85$.

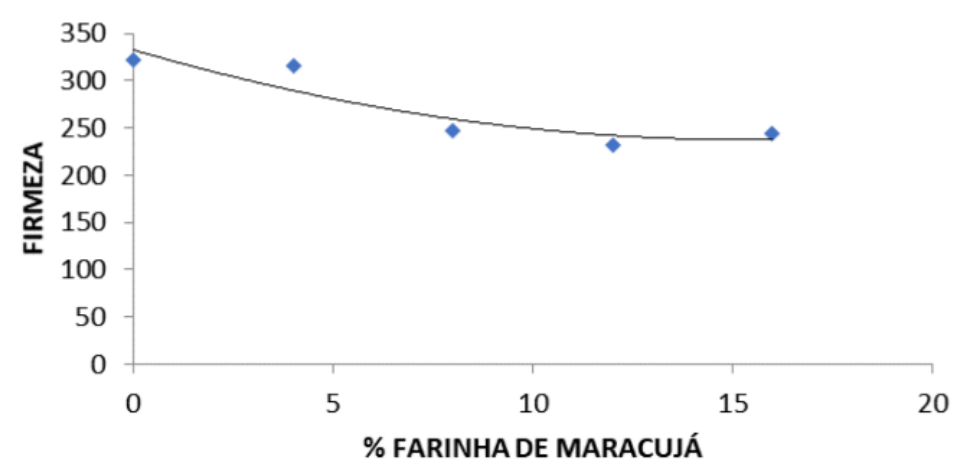

Figura 2: Parâmetro Firmeza no macarrão, em diferentes porcentagens de farinha de maracujá 
A incorporação da FAM gerou uma diminuição do parâmetro firmeza, sendo seu ponto mínimo em $15,41 \%$ de adição da farinha de albedo de maracujá. O uso de produtos não tradicionais interfere na formação da matrix do glúten, enfraquecendo suas ligações, tornado o sistema mais frágil e facilitando a penetração de água [17].

\subsubsection{Força de Cisalhamento}

O parâmetro força de cisalhamento, tem modelo matemático significativo, descrito como $0,041[\mathrm{FAM}]^{2}-1,161$ [FAM] $+23,587 \mathrm{com} \mathrm{R}^{2}=0,94$. Assim como a firmeza, este parâmetro tem seu valor reduzido com o aumento da adição de farinha de maracujá à massa alimentícia, sendo seu valor mínimo com a incorporação de $14,23 \%$ da FAM na sua formulação.

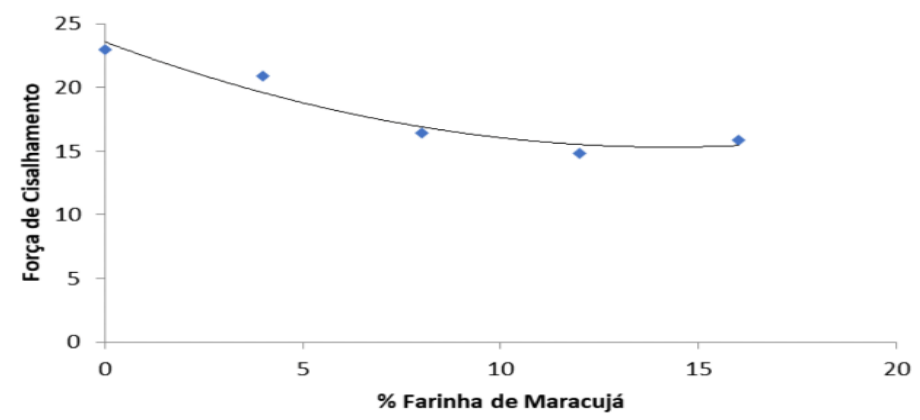

Figura 3: Parâmetro de Força de cisalhamento no macarrão, com diferentes porcentagens de farinha de maracujá

\subsubsection{Biscoito}

\subsubsection{1 Índice de expansão e espessura, perda de peso e massa específica.}

Os resultados obtidos dos índices de expansão e espessura, perda de peso e massa específica não apresentaram um modelo significativo, se tendo como resultados de média e desvio padrão $0,96 \pm 0,01 ; 0,94 \pm 0,38 ; 0,18 \pm 0,01$ e 0,97 \pm 0,15 respectivamente.

\subsubsection{Textura do Biscoito: Dureza e Fracturabilidade}

Os resultados do teste de dureza não mostram um modelo significativo, tendo como média e desvio $5791,26 \pm 692,48$. O aumento no valor de parâmetros relacionados a textura do alimento, como a dureza, vem sendo observado com 0 aumento no teor de fibras no produto [18].

A fracturabilidade, força com que o biscoito se fratura, possui modelo significativo com $\mathrm{Fra}=0,0042[\mathrm{FAM}]^{2}+0,072[\mathrm{FAM}]+0,69 \mathrm{com}^{2}=0,92$. Assim como a dureza, esta cresce com o aumento da incorporação da farinha de maracujá na formulação da massa do biscoito. Isso já era esperado, pois um biscoito mais duro é mais dificilmente rompido, a tensão das forças necessárias para a fratura se tornam maiores. Tendo seu ponto máximo com adição de 8,57\% da FAM. 


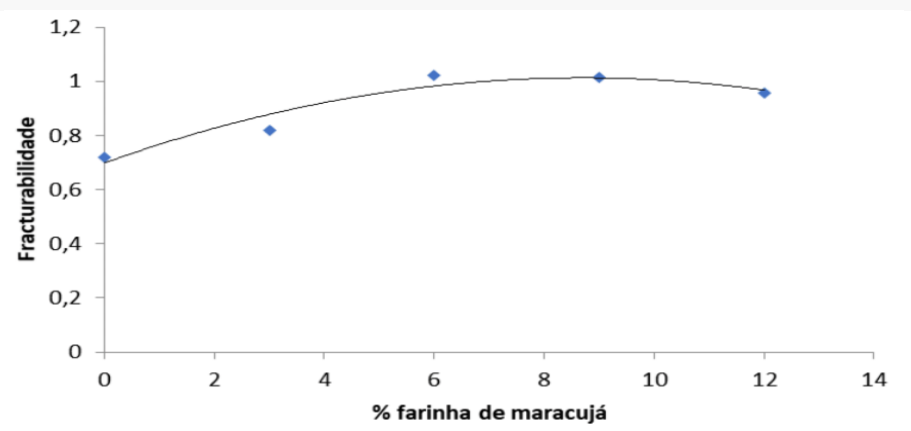

Figura 5: Parâmetro Fracturabilidade no biscoito, em diferentes percentuais de farinha de maracujá.

\section{CONCLUSÃO}

Com base nas análises, se observou que as FAM das variedades amarela e roxa não apresentaram diferenças significativas nos parâmetros analisados. Para o macarrão os melhores resultados, foram na adição de $15 \%$ da FAM onde a força de cisalhamento e a dureza foram mínimos, e a absorção de água foi próxima do esperado. Em relação ao biscoito, a adição da FAM não apresentou grandes resultados significativos. A FAM apresentou problemas tecnológicos, mas melhorias como a uniformização dos grânulos, seriam benéficas, melhorando de forma significativa a qualidade dos produtos panificados.

\section{Agradecimentos}

A agencia de fomento Fapesb, que financiou a bolsa de inovação tecnológica, com número de outorga 0650/2016, permitindo a realização da pesquisa.

\section{REFERÊNCIAS}

1 INSTITUTO BRASILEIRO DE GEOGRAFIA E ESTATíSTICA- IBGE. Produção Agrícola Municipal, 2017. Disponível em: < http://www.cnpmf.embrapa.br/Base de Dados/index pdf/dados/brasil/maracuja/b1 maracuja.pdf> Acesso em: julho 2019

${ }^{2}$ MELETTI, L. M. M. Avanços na cultura do maracujá no Brasil. Revista Brasileira de Fruticultura, Jaboticabal, v.33, 2011.

${ }^{3}$ OLIVEIRA, E. M. S. de; RESENDE, E. D. de. Yield of albedo flour and pectin content in the rind of yellow passion fruit, Ciência e Tecnologia de Alimentos, v.32, n.3, Campinas, July/Sept. 2012. 
${ }^{4}$ FERRARI, R. A.; COLUSSI, F.; AYUB, R. A. Caracterização de subprodutos da industrialização do maracujá-aproveitamento das sementes. Revista Brasileira de Fruticultura. Jaboticabal, v. 26, n. 1, 2004.

${ }^{5}$ DA SILVA, E. C. O.; DA SILVA, W.P.; DA SILVA, E.T.; LOPES, J.D.; GUSMÃO, R.P. de, Obtaining and characterization of passion fruit albedo flour (Passiflora edulis $f$. Flavicarpa) for food use, Revista Verde de Agroecologia e Desenvolvimento Sustentável, v.11, № 3, p. 69-74, 2016.

${ }^{6}$ MATSUURA, F. C. A. U. Estudo do albedo do maracujá e de seu aproveitamento em barras de cereais. 2005. 157 f. Dissertação (Mestrado em Engenharia de Alimentos) -Faculdade de Engenharia de Alimentos, Universidade Estadual de Campinas, Campinas, 2005.

${ }^{7}$ ASSOCIAÇÃO BRASILEIRA DA INDÚSTRIA DE PANIFICAÇÃO E CONFEITARIAABIT; INSTITUTO TECNOLÓGICO- ITPC. Indicadores da panificação e confeitaria 2018, 2018. Disponível em: < http://www.agenciazaga.com/INDICADORES-DAPANIFICA\%C3\%87\%C3\%830-E-CONFEITARIA\%20BRASILEIRA\%202018.pdf>

Acesso em: julho 2019.

${ }^{8}$ BRASIL. Agencia Nacional de Vigilância Sanitária- ANVISA. Resolução RDC no 263, de 22 de setembro de 2005, Regulamento Técnico para produtos de cereais, amidos, farinhas e farelos, 2005.

9 FERNANDES, A.F.; PEREIRA, J.; GERMANI, R.; OIANO- NETO, J., Effect of the partial replacement of wheat flour for potato skin flour (Solanum Tuberosum L.), Ciência e Tecnologia de Alimentos, Campinas, v. 28, p. 56-65, dez. 2008

10 AMERICAN ASSOCIATION OF CEREAL CHEMISTS- AACC. Approved Methods, 10th ed., St. Paul: AACC, 2000.

${ }^{11}$ FRANCO, V. A. Desenvolvimento de pão se glúten de farinha de arroz e batata doce.2015. 129 f. Dissertação (Mestrado em Ciência e Tecnologia de Alimentos) -Escola de Agronomia, Universidade Federal de Goiás, Goiânia. 2015.

${ }^{12}$ SILVA, R. F.; ASCHERI, J. L. R.; PEREIRA, R. G. F. A. Composição centesimal e perfilde aminoácidos de arroz e pó de café. Alimentos e Nutrição, Araraquara. v.18, n. 3, p. 325-330, 2007

${ }^{13}$ SOUZA, M. W. S. de; FERREIRA, T. B. O; VIEIRA, I. F. R.Composição centesimal epropriedades funcionais tecnológicas da farinha da casca do maracujá. Alimentos e Nutrição, Araraquara-SP, v. 19, n.1, p. 33-36, jan-mar 2008 
${ }^{14}$ MINGUITA et al. Produção e caracterização de massas alimentícias a base de alimentos bio fortificados: trigo, arroz polido e feijão carioca com casca. Ciência Rural, Santa Maria, v.45, n.10, p.1895-1901, out, 2015

${ }^{15}$ MARTINS, J. N.; OLIVEIRA, E. N. A. de; SANTOS, D. da C. Estudo da absorção de água em misturas de farinhas de trigo em diferentes marcas comerciais. Revista Verde, Mossoró-RN, v. 7, n. 4, p. 201-206, out-dez 2012

${ }^{16}$ HUMMEL, C. Macaroni products. London: Food Trade Press, 1966, 287p

${ }^{17}$ COSTA, T. V. M., MOURA, C. M. A. de, SOARES JUNIOR, M. S. Qualidade tecnológica de massa alimentícia produzida a partir de farinhas de arroz e linhaça. Escola de Agronomia e Engenharia de Alimentos-Universidade Federal de Goiás, 2013

${ }^{18} \mathrm{HADDAD}, \mathrm{F} . \mathrm{F}$. Barras alimentícias de sabor salgado com diferentes agentes ligantes: aspectos tecnológicos, sensorial e nutricional. Lavras-MG, UFLA, 2013 